\title{
Developing Postmitotic Mammalian Neurons In Vivo Lacking Apaf-1 Undergo Programmed Cell Death by a Caspase-Independent, Nonapoptotic Pathway Involving Autophagy
}

\author{
Ronald W. Oppenheim, ${ }^{1}$ Klas Blomgren, ${ }^{2}$ Douglas W. Ethell, ${ }^{3}$ Masato Koike, ${ }^{4}$ Masaaki Komatsu, ${ }^{5}$ David Prevette, ${ }^{1}$ \\ Kevin A. Roth, ${ }^{6}$ Yasuo Uchiyama, ${ }^{4}$ Sharon Vinsant, ${ }^{1}$ and Changlian $\mathrm{Zhu}^{2}$ \\ ${ }^{1}$ Department of Neurobiology and Anatomy and the Neuroscience Program, Wake Forest University School of Medicine, Winston-Salem, North Carolina \\ 27157, ${ }^{2}$ Center for Brain Repair and Rehabilitation, Institute of Neuroscience and Physiology, Göteborg University, and Department of Pediatric Oncology, \\ The Queen Silvia Children's Hospital, SE 40530 Göteborg, Sweden, ${ }^{3}$ Department of Biomedical Sciences, University of California, Riverside, California \\ 92521, ${ }^{4}$ Department of Cell Biology and Neuroscience, Osaka University, Osaka 565-0871, Japan, ${ }^{5}$ Department of Biochemistry, Juntendo University, Tokyo \\ 113-8421, Japan, and 'Department of Pathology, University of Alabama, Birmingham, Alabama 35294
}

Previous studies have shown that caspases and Apaf-1 are required for the normal programmed cell death (PCD) in vivo of immature postmitotic neurons and mitotically active neuronal precursor cells. In contrast, caspase activity is not necessary for the normal PCD of more mature postmitotic neurons that are establishing synaptic connections. Although normally these cells use caspases for PCD, in the absence of caspase activity these neurons undergo a distinct nonapoptotic type of degeneration. We examined the survival of these more mature postmitotic neuronal populations in mice in which Apaf- 1 has been genetically deleted and find that they exhibit quantitatively normal PCD of developing postmitotic neurons. We next characterized the morphological mode of PCD in these mice and show that the neurons degenerate by a caspase-independent, nonapoptotic pathway that involves autophagy. However, autophagy does not appear to be involved in the normal PCD of postmitotic neurons in which caspases and Apaf- 1 are present and functional because quantitatively normal neuronal PCD occurred in the absence of a key gene required for autophagy (ATG7). Finally, we examined the possible role of another caspase-independent type of neuronal PCD involving the apoptosis-inducing factor (AIF). Mice deficient in AIF also exhibit quantitatively normal PCD of postmitotic neurons after caspase inhibition. Together, these data indicate that, when key components of the type 1 apoptotic pathway (i.e., caspases and Apaf-1) are perturbed in vivo, developing postmitotic neurons nonetheless undergo quantitatively normal PCD by a caspase-independent pathway involving autophagy and not requiring AIF.

Key words: neuron; cell death; mouse; Apaf-1; autophagy; AIF; ATG7

\section{Introduction}

During embryonic and postnatal development of many vertebrate species, a large-scale loss of differentiating and neuronal precursor cells occurs as a normal, required stage in nervous system maturation (Oppenheim, 1991; Boya and de la Rosa, 2005; Buss et al., 2006). Although this normal programmed cell death (PCD) can occur by distinct morphological pathways (Clarke, 1990, 1998), the biochemical and molecular pathways involved have been generally considered to require a relatively conserved core of so-called "proapoptotic" genes comprised of

Received 0ct. 8, 2007; revised Dec. 6, 2007; accepted Dec. 10, 2007.

This work was supported by National Institutes of Health Grants NS20402, NS536945, and NS053527 (R.W.O.), AG1652 (D.W.E.), and NS35107 and NS41962 (K.A.R.); by the Japan Society for the Promotion of Science Grant 16GS0315 (Y.U.); and by the Swedish Research Council and the Swedish Child Cancer Foundation (K.B.).

Correspondence should be addressed to Ronald W. Oppenheim at the above address. E-mail: roppenhm@wfubmc.edu.

DOI:10.1523/JNEUROSCI.4575-07.2008

Copyright $\odot 2008$ Society for Neuroscience $\quad$ 0270-6474/08/281490-08\$15.00/0
Bcl-2 family members, the apoptosome (cytochrome $c$, Apaf-1, caspase 9) and downstream caspases (e.g., caspase-3). The most compelling evidence for the role of this core cell death pathway in the nervous system is the demonstration of reduced PCD in mice lacking caspase-3, caspase-9, cytochrome $c$, or Apaf-1 (Kuida et al., 1996, 1998; Cecconi et al., 1998; Hakem et al., 1998; Yoshida et al., 1998; Kuan et al., 2000; Hao et al., 2005). A common phenotype in all of these mutant mice is a massive overgrowth of cells in the brain (exencephaly) that was attributed in part to reduced PCD of both immature neurons and dividing neuronal precursor cells. These studies clearly demonstrate that the extensive PCD of immature postmitotic neurons and mitotically active progenitor cells in the nervous system require cytochrome $c$, Apaf- 1 , and caspases. However, a considerable amount of PCD in the developing nervous system also involves more mature differentiating postmitotic neurons that are establishing synaptic connections, and this aspect of neuronal PCD was not examined in the abovementioned studies. We previously reported that the extent of 
neuronal PCD during this later phase is unaffected by the genetic deletion of either caspase-3 or caspase-9 (Oppenheim et al., 2001a) and the PCD of postmitotic motor neurons (MNs) in the chick embryo has also been shown to be unaffected after the pharmacological inhibition of caspases (Yaginuma et al., 2001). In the present study, we examined PCD in several populations of target-dependent neurons in Apaf-1 knock-out (KO) mice, and contrary to a previous report (Honarpour et al., 2001a), we find that PCD occurs to the same extent as in wild-type (WT) control animals.

To determine whether the proapoptotic apoptosis-inducing factor (AIF) is involved in the normal PCD of developing neurons or in PCD after caspase inhibition, we also examined the survival of neurons in Harlequin ( $\mathrm{Hq}$ ) mutant mice in which the AIF is reduced by $80 \%$ in adult animals (Klein et al., 2002). AIF has been shown to be involved in PCD during early embryogenesis (Joza et al., 2001; Cheung et al., 2006) and in injury-induced cell death in the neonatal and adult brain (Blomgren et al., 2007; Cao et al., 2007). Finally, because we show here that neuronal PCD in the absence of Apaf- 1 exhibits an autophagic morphology, we also examined whether normal neuronal PCD during development is perturbed by the loss of one of the key genes involved in autophagy, ATG7 (Yu et al., 2004; Levine and Yuan, 2005; Komatsu et al., 2006).

\section{Materials and Methods}

Animals. We used two separate lines of Apaf-1-null mice. One was derived from founder chimeric males generated from 129/SV-derived ES cells and mated with outbred NMRI females, and heterozygote progenies were mated to maintain the allele (Cecconi et al., 1998). The other line was derived from heterozygous mutant ES cells used to generate chimeras. Chimeric mice were backcrossed to a CD1 strain to generate heterozygotes for the Apaf-1 mutation (Yoshida et al., 1998). All homozygote Apaf-1-null mice used here exhibited exencephaly and all genotypes were confirmed by PCR. The forebrain overgrowth ( $f \circ g$ ) mice were obtained from The Jackson Laboratory (Bar Harbor, ME) and heterozygote $(f \circ g /+)$ breeder pairs were used to generate homozygote ( fog/fog) mutant embryos. The adult fog mutants were derived from fog+/-, Apaf$1+/-$ crosses (Honarpour et al., 2001a,b). Animals were classified as homozygotes if they exhibited exencephaly/head deformations characteristic of fog/fog mutants (Harris et al., 1997; Honarpour et al., 2001a,b). Because the Apaf- 1 gene is located in the minimal region to which the fog mutation has been mapped, this as well as other evidence indicates that the fog mutant is attributable to a hypomorphic Apaf- 1 defect (Honarpour et al., 2001a,b). Finally, the ATG7 tissue used here came from mice maintained in the laboratory of Dr. Y. Uchiyama (Osaka University, Osaka, Japan); the Hq tissue was provided by Dr. Klas Blomgren (Göteborg University, Göteborg, Sweden); the Apaf-1 tissue was provided by Dr. Doug Ethell (University of California, Riverside, CA) and Dr. Kevin Roth (University of Alabama, Birmingham, AL); and the adult fog tissue was from Dr. Doug Ethell. The procedures for generating the tissues used in this study were approved by the Animal Care and Use Committees at the institution involved and compiled with the National Institutes of Health Guidelines for the Care and Use of Laboratory Animals.

Histology and neuron quantification. Embryos were anesthetized by hypothermia and spinal cords and brains were immersion fixed in Bouin's solution for several days and processed for paraffin embedding. Adult mice were anesthetized by an overdose of ketamine/xylazine followed by perfusion with Bouin's solution. Tissue [brain, spinal cord, superior cervical sympathetic ganglia (SCGs)] were dissected and processed for paraffin sectioning. Serial transverse sections $(6-8 \mu \mathrm{m})$ were obtained from embryonic, postnatal, and adult mice, and stained with either hematoxylin-eosin (H\&E) or thionin, and neurons were counted blind in every 5th (brain) or 10th (spinal cord, SCG) section using a method previously validated against a stereological optical disector method (Clarke and Oppenheim, 1995) (R. W. Oppenheim, unpub- lished data). As previously described in chick embryos after treatment with caspase inhibitors (Yaginuma et al., 2001), and in mouse embryos with genetic deletion of caspase- 3 or caspase- 9 (Oppenheim et al., 2001a; present study), the morphology of degenerating neurons in these embryos differs from the typical type 1 apoptotic cell death observed in control/WT embryos (see Results). For this reason, the analysis of degenerating cells in the Apaf- 1 mutants also includes these atypical presumptive dying neurons. Estimates of total neuron numbers in each population were obtained by multiplying final values by 5 or 10 . Spinal MN (lumbar) and dorsal root ganglion (DRG) numbers in the fourth or fifth lumbar [DRG (L4, L5)] on embryonic day 12.5 (E12.5) were obtained using antibodies against HB9 (MNs) or islet 1-2 (DRG) (see below, Immunocytochemistry and TUNEL). All cell counts were done blinded by a single observer.

The quantification of terminal deoxynucleotidyl transferase-mediated biotinylated UTP nick end labeling-positive $\left(\mathrm{TUNEL}^{+}\right.$) and active caspase $-3^{+}$spinal MNs and DRG cells was done from every 30 th, $16 \mu \mathrm{m}$ section through the lumbar spinal cord and through the L4-L5 DRG on E14. Spinal cord interneurons (INs) were counted in one-half (hemisection) of the lumbar spinal cord excluding the ventral and dorsal horns as previously described (Grieshammer et al., 1998).

Immunocytochemistry and TUNEL. After anesthesia by hypothermia and decapitation, embryos were immersion fixed in $4 \%$ paraformaldehyde in $0.1 \mathrm{M}$ PBS, pH 7.4, overnight at $4^{\circ} \mathrm{C}$. After cryoprotection in $30 \%$ sucrose overnight, lumbar spinal cords with DRG were then frozen in a solution of $30 \%$ sucrose and Tissue-Tek embedding medium (Miles, Elkhart, IN). Transverse cryostat sections $(16 \mu \mathrm{m})$ through the lumbar region were collected and stored at $-20^{\circ} \mathrm{C}$ until additional processing. Subsequently, sections were blocked in $10 \%$ normal goat serum and $0.1 \%$ Triton X-100 in PBS for 30 min, followed by incubation with primary antibodies against anti-activated caspase- 3 or caspase-7 (1:100; Cell Signaling Technology, Beverly, MA) or mouse anti-islet-1 (1:100; Developmental Studies Hybridoma Bank, Iowa City, IA). For double immunofluorescent staining for caspases and TUNEL in postnatal day 15 (P15) ATG7 mice, cryosections were incubated with anti-cleaved caspase-3 (1:100), or caspase-7 $(1: 100)$ at $4^{\circ} \mathrm{C}$ overnight, followed by goat antirabbit IgG coupled with Alexa Fluor 488 (Invitrogen, Carlsbad, CA) for $1 \mathrm{~h}$ at room temperature. After immunostaining, TUNEL staining was performed using an in situ cell death detection kit, TMR red (Roche Diagnostics, Mannheim, Germany) according to the manufacturer's recommended protocol. Granule cells in the dentate gyrus (DG) of the hippocampus were then viewed under a confocal laser-scanning microscope (FV1000; Olympus, Tokyo, Japan). On E13.5, MNs were also counted using a rabbit antibody to the MN-specific HB9 transcription factor $(1: 10,000)$ kindly provided by Dr. S. Pfaff (The Salk Institute, San Diego, CA) (Thaler et al., 1999) as described previously (Winseck and Oppenheim, 2006). For identification of fragmented DNA in paraffinembedded 6-8 $\mu \mathrm{m}$ tissue sections on E14, the TUNEL technique was used according to the manufacturer's instructions (Apotag Peroxidase In Situ Apoptosis Detection kit; Chemicon, Temecula, CA). For the detection of activated caspase- 3 in paraffin-embedded sections, the sections were incubated with the same caspase- 3 antibody described above, followed by peroxidase-conjugated $\mathrm{ABC}$ complex (vector), and the positive reaction was visualized with $\mathrm{DAB}$.

Electron microscopy. Because of the difficulty in perfusing E13-E14 embryonic mice, immersion fixation was used. Pregnant females were anesthetized and packed in ice. Embryos were removed as quickly as possible, placed on ice, decapitated, and eviscerated, and immersed in $2 \%$ glutaraldehyde, $2 \%$ paraformaldehyde in $0.13 \mathrm{~m}$ sodium cacodylate buffer, $\mathrm{pH} 7.3$, at $4^{\circ} \mathrm{C}$ for $1-3 \mathrm{~d}$. Tissue was then further dissected by embedding in $4 \%$ low temperature agarose and cut at $300 \mu \mathrm{m}$ on a vibratome. After viewing with transillumination, sections containing the lumbar motor column were osmicated and embedded in Araldite 502 using a Lynx tissue processor. One micrometer sections were cut using the LKB Ultratome V and counterstained with toluidine blue. If fixation was sufficiently good, subsequent adjacent $700 \AA$ thin sections were collected onto Formvar-coated slot grids and stained in methanolic uranyl acetate and lead citrate for viewing with a Zeiss (Oberkochen, Germany) EM 10C. 
Caspase inhibition. A broad-spectrum caspase inhibitor quinolineVal-Asp (OMe)- $\mathrm{CH}_{2}-\mathrm{PH}(\mathrm{Q}-\mathrm{VD}-\mathrm{OPH})$ (Enzyme Systems Products, Livermore, CA) was dissolved in $100 \%$ DMSO and diluted with saline. Hq mice and their WT controls were injected daily intraperitoneally at a dose of $5 \mathrm{mg} / \mathrm{kg}$ ( $10 \mu \mathrm{l} / \mathrm{g}$ body weight) for $3 \mathrm{~d}$ starting at P2. Controls received an equal volume of saline containing 10\% DMSO (vehicle). On P4.5-P5, pups were deeply anesthetized with $50 \mathrm{mg} / \mathrm{ml}$ phenobarbital and perfusion fixed with either Bouin's solution for histology or 5\% paraformaldehyde in $0.1 \mathrm{~m}$ PBS for TUNEL (see above). In addition, a subset of animals from this experiment were used for a caspase- 3 activity assay using one cortical hemisphere as described previously (Wang et al., 2001). Homogenate samples $(25 \mu \mathrm{l})$ were mixed with $75 \mu \mathrm{l}$ of extraction buffer and the cleavage of AC-DEVD-AMC (acetyl-DEVD-7-amido-4methylcoumarin) (Peptide Institute, Osaka, Japan) was used to measure caspase-3-like activity. Detection of AMC was performed with an excitation wavelength of $380 \mathrm{~nm}$ and an emission wavelength of $460 \mathrm{~nm}$ and expressed as picomoles of AMC released per milligram of protein per minute. The other cortical hemisphere was immersion fixed in 5\% paraformaldehyde and processed for the TUNEL reaction as described above; the number of TUNEL ${ }^{+}$cells in the granule and subgranule cell layers of the DG was counted in three sections per animal containing both blades of the rostral DG.

\section{Results}

\section{Animals}

As previously described, all Apaf-1-null embryos (confirmed by PCR) exhibited forebrain exencephaly regardless of genetic background (Cecconi et al., 1998; Yoshida et al., 1998). The forebrain overgrowth ( fog) mutant embryos also exhibited forebrain exencephaly that was grossly similar to that observed in Apaf-1-null mice as well as mild-to-moderate lumbar spina bifida (Harris et al., 1997; Honarpour et al., 2001a,b). A few homozygous fog/fog mutants survived to adulthood and also exhibited forebrain exencephaly, but unlike the embryos, the exencephalic forebrain was covered by hairy skin and appears as forehead bumps (Harris et al., 1997). The three adult fog mutants examined here exhibited this phenotype. With the exception of neural tube defects (exencephaly, spina bifida) and an apparent delay in interdigital PCD described previously (Yoshida et al., 1998), Apaf-1 and fog mutant animals appeared otherwise grossly normal.

\section{Quantitative assessment of neuron numbers}

Regardless of the methods used to label and count neurons (Nissl, HB9, or islet-1), the number of spinal MNs and DRG neurons on E13-E14 did not differ between WT and Apaf-1 or fog mutant embryos (supplemental Table 1, available at www.jneurosci.org as supplemental material). Because the normal PCD of these populations of neurons is either just beginning (spinal MNs) or not completed (DRG) on E13, we also counted neurons in these and other populations at E18.5 and again found no differences between WT and Apaf-1 mutants ( fog mutants were not examined) (Fig. 1A, $B$, Table 1). Because the normal PCD of some populations of neurons continues postnatally, we also counted neurons in adult fog mutant animals. There were no differences in neuron numbers between adult control and fog mutant animals in any of the neuronal populations examined (supplemental Table 2, available at www.jneurosci.org as supplemental material). These included spinal and cranial MNs, spinal interneurons, DRG sensory neurons, and sympathetic neurons in the SCG. Together, these data indicate that many populations of postmitotic, "target-dependent" neurons undergo a quantitatively normal amount of PCD in the absence of Apaf-1.

\section{The phenotype of dying neurons in the absence of Apaf-1}

Although the most common mode of PCD of developing postmitotic neurons is apoptotic-like (type 1) (Clarke, 1990), previ-

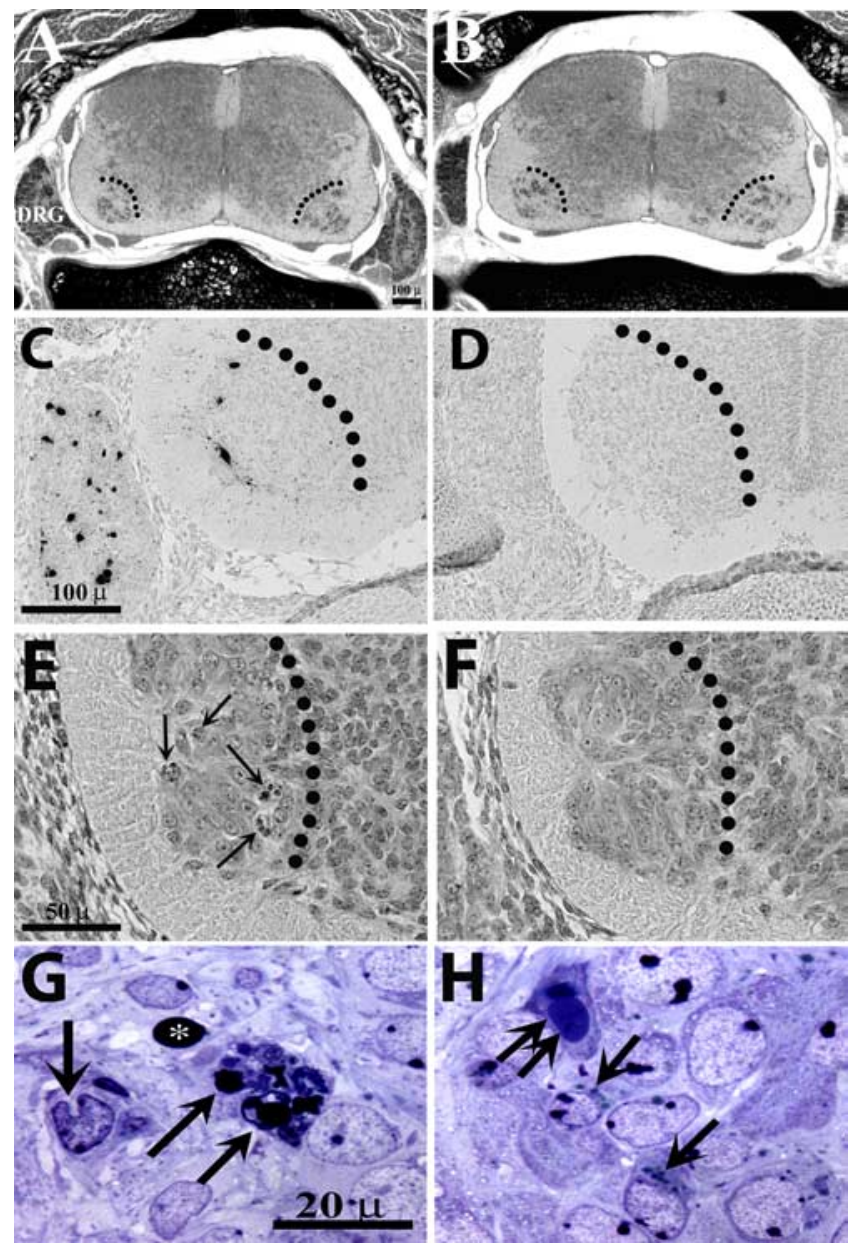

Figure 1. $\quad \boldsymbol{A}, \boldsymbol{B}$, Images of Nissl-stained sections from the midlumbar spinal cord on E18.5 of WT control $(\boldsymbol{A})$ and Apaf-1 KO $(\boldsymbol{B})$ embryos. The dotted line is the medial border of the ventral horn. $\mathbf{C}-\boldsymbol{H}$, Images of the ventral horn (the dotted line is the medial border) in the midlumbar spinal cord on E14. C, D, Expression of activated caspase-3 in MNs in the ventral horn and sensory neurons in the DRG of WT control $(\boldsymbol{C})$ and Apaf-1 K0 embryos $(\boldsymbol{D}) . \boldsymbol{E}, \boldsymbol{F}$, Nissl-stained images of the lumbar spinal cord showing pyknotic/apoptotic MNs (arrows) in WT control $(\boldsymbol{E})$ versus Apaf-1 KO $(\boldsymbol{F}) . \mathbf{G}, \boldsymbol{H}$, Toluidine blue-stained, $1 \mu \mathrm{m}$ plastic-embedded sections of WT $(\boldsymbol{G})$ and Apaf- $1 \mathrm{KO}(\boldsymbol{H})$. In $\boldsymbol{G}$, the double arrow shows a $M N$ undergoing late-stage type $1 P C D$, and the single arrow shows a $M N$ at an early stage of type $1 P C D$. In $H$, the single arrows indicate unusual L-like profiles in the cytoplasm that are never seen in WT MNs. The double arrows in $\boldsymbol{H}$ show a MN that appears to be at a later stage of PCD but with the nucleus still intact, and the asterisk in $G$ indicates a pyknotic MN nucleus.

\section{Table 1. Neuron numbers at E18.5}

\begin{tabular}{lcc}
\hline Cells & Control & Apaf-1 \\
\hline MNs & & \\
$\quad$ Brachial & $3117 \pm 787(n=8)$ & $3009 \pm 665(n=6)$ \\
$\quad$ Thoracic & $3265 \pm 662(n=8)$ & $3131 \pm 553(n=6)$ \\
$\quad$ Lumbar & $2438 \pm 512(n=7)$ & $2390 \pm 575(n=6)$ \\
$\quad$ Hypoglossal & $1520 \pm 91(n=7)$ & $1476 \pm 112(n=6)$ \\
$\quad$ Facial & $3416 \pm 803(n=7)$ & $3288 \pm 913(n=6)$ \\
Spinal (L1-L5) INs & $27,542 \pm 2025(n=4)$ & $26,116 \pm 1716(n=4)$ \\
DRGs (L4) & $8335 \pm 1015(n=5)$ & $8641 \pm 954(n=4)$ \\
\hline
\end{tabular}

Values are expressed as mean \pm SD.

ous studies have shown that, after the genetic deletion or pharmacological inhibition of caspases, postmitotic neurons undergo PCD in vivo and in vitro by a caspase-independent, nonapoptotic pathway (Xue et al., 1999; Oppenheim et al., 2001a; Yaginuma et al., 2001; Cheung et al., 2005; Wright et al., 2007). One of the first 


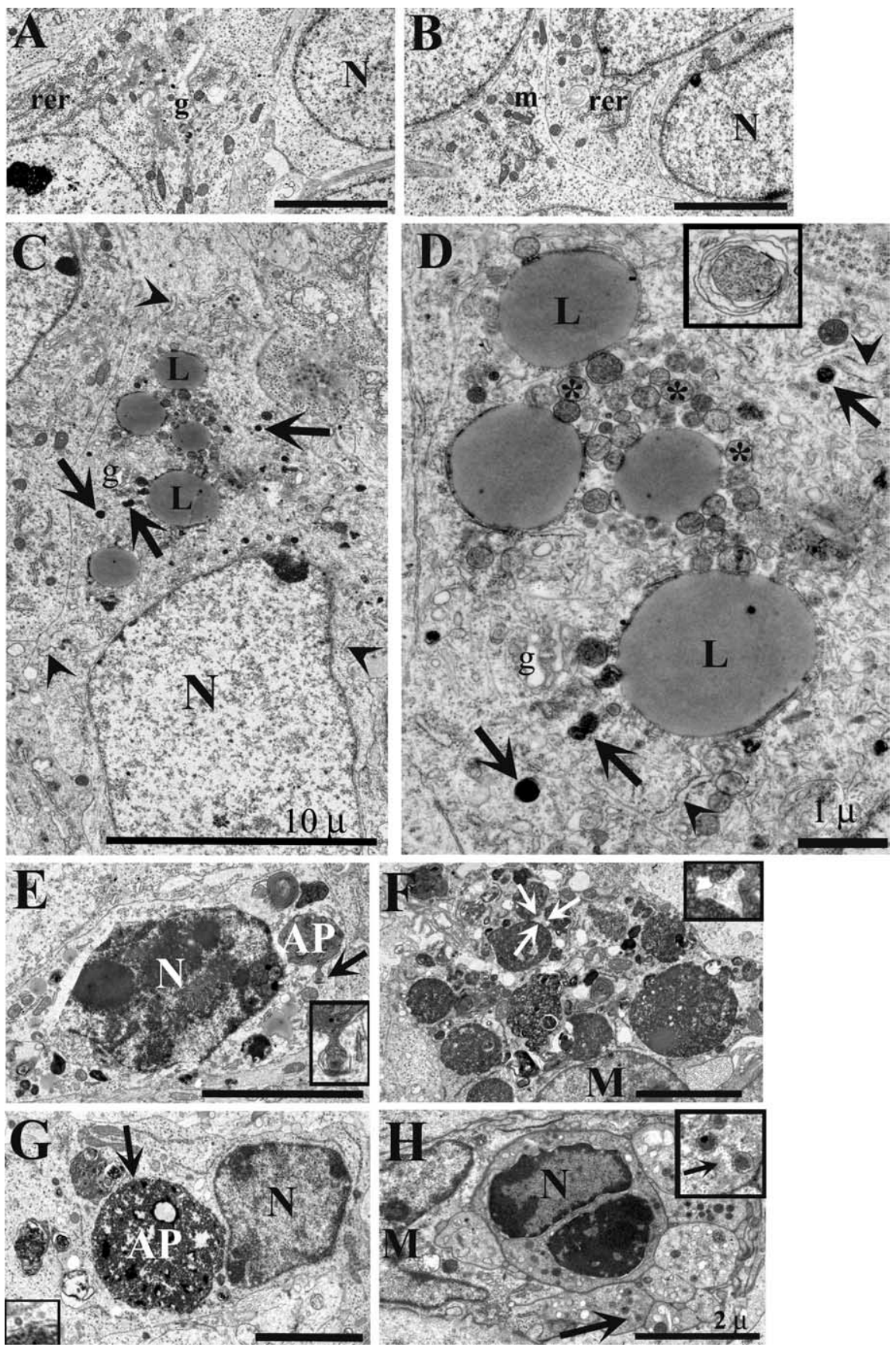

Figure 2. $\quad \boldsymbol{A}$ and $\boldsymbol{B}$ show the normal morphology of most MNs at E14 in both WT and Apaf-KO animals, respectively. The nuclei (N) contain homogenously dispersed chromatin with nucleoli, mitochondria $(\mathrm{m})$ appear compact with distinct cristae, RER is abundant with many ribosomes, and stacked golgi (g) are common. $\boldsymbol{C}$ and $\boldsymbol{D}$ (enlarged field from $\boldsymbol{C}$ ) illustrate the striking appearance of early-stage cell death commonly seen in Apaf-KO resembling autophagy, with the rounding up of cytoplasmic constituents, particularly swollen mitochondria $\left(^{*}\right)$, and swollen RER (arrowheads), into areas rich in Ls and containing APs (arrows). Hypertrophied golgi (g) are also a common feature. The inset in $\boldsymbol{D}$ clearly shows the double membrane of APs. Note the similarity to the $1 \mu \mathrm{m}$ images seen in Figure $1 H$, single arrows. $\boldsymbol{E}, \boldsymbol{F}$, Progressive stages of apoptotic cell death (PCD) in WT animals. Notice the pronounced shrinkage as well as clumping and condensation of the nuclear chromatin (N) as well as an AP in $\boldsymbol{E}$. The arrow points to the area enlarged in the inset showing the double membranes characteristic of APs. By the final stages, as seen in $\boldsymbol{F}$, only apoptotic bodies surrounded by a macrophage $(M)$ remain; the enlarged area shows the single membranes surrounding three apoptotic bodies indicated by the arrows. Note the similarity to the $1 \mu \mathrm{m}$ image in Figure $1 G$, double arrows. $\boldsymbol{G}, \boldsymbol{H}$, In the later stage of autophagic-like cell death $(\boldsymbol{G})$, the nucleus $(\mathrm{N})$ remains fairly normal until quite late in the process $(\boldsymbol{H})$ and even then is still intact. In $\mathbf{G}$, a very large AP can be seen; the arrow points to an area along its boundary that is enlarged in the inset to show the characteristic double membranes of APs. Also note the paucity of organelles in the cytoplasm. This cell appears similar to the $1 \mu \mathrm{m}$ image in Figure $1 \boldsymbol{H}$, double arrows. At a late stage $(\boldsymbol{H})$, the cell is surrounded by a macrophage $(\mathrm{M})$ with portions of the cytoplasm sequestered into profiles containing APs (the area indicated by the large arrow corresponds to the small arrow in the inset showing double membranes of APs). Scale bars, $5 \mu \mathrm{m}$ (unless otherwise indicated). studies suggesting that this atypical PCD of developing neurons involves autophagy was the report of Xue et al. (1999). Accordingly, we next asked whether the PCD of neurons in vivo in Apaf-1 mutant mice undergo an apoptotic-like degeneration. To address this question we focused primarily on MNs and DRG neurons at embryonic stages (E13-E14) when dying WT neurons exhibit nuclear pyknosis, activated caspase-3 expression, and TUNEL (i.e., apoptotic type $1 \mathrm{PCD}$ ).

As expected, many WT MNs and DRG neurons exhibited caspase- 3 activation (Fig. 1C) and TUNEL (data not shown), whereas at the age examined (E14) neither of these neuronal populations in Apaf-1 mutant embryos (Fig. 1D) exhibited these markers of apoptotic-like degeneration. In control embryos $(n=5)$, there were $2.2 \pm$ 0.9 and $2.6 \pm 1.1$ caspase $-3^{+}$cells per section in the ventral horn (MNs) and DRG, respectively, versus no positive cells in Apaf-1-null embryos. Similarly, in control embryos $(n=6)$, there were $1.8 \pm 0.5$ and $3.6 \pm 1.1 \mathrm{TUNEL}^{+}$cells per section in the ventral horn and DRG, respectively, versus no positive cells in Apaf-1-null embryos. Because it has been reported that the PCD of neurons in caspase and Apaf-1 mutants may be delayed by 1-2 d (Yoshida et al., 1998; Yaginuma et al., 2001; Cregan et al., 2002; Cheung et al., 2005), we also looked for both TUNEL labeling and caspase-3immunolabeled spinal MNs on E16.5 and E18.5 in WT and Apaf-1 embryos. Although WT embryos exhibited MNs labeled by both markers at these ages (but much less than at E13-E14), no labeled MNs were observed in mutant embryos (data not shown). However, there were MNs and DRG cells in E14 and E18 mutant embryos that, in the light microscope, exhibited degenerative-like changes virtually never seen in WT embryos. In the populations of developing neurons we examined, it is quite easy to detect degenerating neurons in $\mathrm{H} \& \mathrm{E}$ - or Nissl-stained sections from control animals (Fig. 1E), whereas similar cells are seldom if ever seen in sections from Apaf-1/fog mutants (Fig. $1 F$ ). When neurons from mutant animals were examined in $1 \mu \mathrm{m}$ plastic-embedded sections, however, it was possible to more clearly discern cells that, based on subsequent ultrastructural observations, appear to be degenerating by a morphological pathway distinct from PCD in WT animals (Fig. 2, compare $G, H)$. As described below, when these cells are examined in the electron microscope, they contain autophagosomes (APs), lysosomes (Ls), and other alterations characteristic of autophagy. 
Table 2. Neuron numbers at P5 (control/Hq) and P15 (WT/ATG7)

\begin{tabular}{|c|c|c|c|c|c|c|}
\hline \multirow[b]{2}{*}{ Cells } & \multicolumn{2}{|l|}{ Control } & \multicolumn{2}{|l|}{ Hq mutant } & \multicolumn{2}{|l|}{ ATG7 } \\
\hline & Saline/DMSO & QVD & Saline/DMSO & QVD & WT & KO \\
\hline Lumbar (L1-L5) MNs & $2351 \pm 309(n=5)$ & $2394 \pm 303(n=5)$ & $2258 \pm 309(n=5)$ & $2331 \pm 282(n=5)$ & $2347 \pm 315(n=4)$ & $2430 \pm 277(n=7)$ \\
\hline Hypoglossal MNs & $1317 \pm 83(n=5)$ & $1277 \pm 76(n=5)$ & $1195 \pm 118(n=5)$ & $1278 \pm 109(n=5)$ & $1297 \pm 110(n=4)$ & $1313 \pm 119(n=4)$ \\
\hline Facial MNs & $2449 \pm 261(n=5)$ & $2513 \pm 164(n=5)$ & $2561 \pm 201(n=5)$ & $2629 \pm 215(n=5)$ & $2621 \pm 170(n=4)$ & $2553 \pm 141(n=4)$ \\
\hline Trigeminal MNs & $685 \pm 70(n=5)$ & $720 \pm 90(n=5)$ & $687 \pm 88(n=5)$ & $732 \pm 71(n=5)$ & $665 \pm 59(n=4)$ & $735 \pm 76(n=4)$ \\
\hline SCGS & $13,880 \pm 1166(n=5)$ & $14,815 \pm 1181(n=5)$ & $13,336 \pm 1099(n=5)$ & $14,400 \pm 1171(n=5)$ & $13,191 \pm 1003(n=4)$ & $14,219 \pm 1207(n=4)$ \\
\hline
\end{tabular}

Values are expressed as mean \pm SD.

\section{Evidence for PCD by an autophagic pathway in Apaf-1 mutants}

Although the mode of PCD of developing neurons in Apaf-1/fog mutants is distinct from WT animals when examined in the light microscope (Fig. 1), the cellular basis of this difference could only be clearly discerned at the ultrastructural level. In WT embryos, type I apoptotic cell death (PCD) is observed in lumbar MNs (Fig. $2 E, F)$. Motoneurons with normal ultrastructure are common in both genotypes (Fig. 2A,B), with large cell bodies and round nuclei containing diffuse, pale chromatin and frequent dark nucleoli, as well as cytoplasm rich in organelles. In the early stages of type 1 PCD (Fig. 2E), the nuclear chromatin condenses and some clumping is observed; the appearance of mitochondria is normal, but there is a paucity of ribosomes on the rough endoplasmic reticulum (RER), and an occasional autophagosome can be seen. At later stages, apoptotic bodies are engulfed by phagocytes (Fig. $2 F)$. Note the single-membrane-bound apoptotic bodies in the inset of Figure $2 F$ compared with the double-membrane APs in Figure 2, E, G, and $H$.

In contrast, in Apaf KO MNs $(n=4)$ type 1 PCD was not observed. Rather, MNs in the Apaf- $1 \mathrm{KO}$ exhibit features characteristic of type 2 autophagic PCD (Fig. $2 C, D, G, H$ ). Close examination of $1 \mu \mathrm{m}$ sections by light microscopy showed Apaf-1 KO MNs with normal nuclei but atypical cytoplasm (Fig. $1 \mathrm{H}$, single arrows) that may correspond to the increased presence of Ls and APs seen at the EM level in Figure 2, C, D, G, and $H$. Although it is sometimes difficult to distinguish lysosomes from lipid droplets, the structures we observe appear to more closely exhibit the characteristics of lysosomes (Peters et al., 1976): spherical or oval; single-membrane bound; $0.3-0.5 \mu \mathrm{m}$, but often $1-2 \mu \mathrm{m}$ in neurons; and in developing neurons, the contents of lysosomes appear homogeneous. Even at a late stage (Fig. $2 H$ ), these degenerating cells do not display apoptotic profiles as seen in type 1 PCD (Fig. 2 F). In early stages of PCD in Apaf-1 KO MNs, the nucleus appears normal (Fig. 2C), whereas cell organelles appear aggregated into an area with many Ls and APs (Fig. 2C, enlarged in D). Mitochondria are adversely affected, with loss of cristae and a swollen, rounded appearance (asterisks); the RER becomes dilated (Fig. 2D, inset, arrowhead); and hypertrophy of Golgi (g) is also common. As the degeneration proceeds (Fig. $2 G$ ), both the cytoplasm and nucleus become more condensed although less than in type 1 PCD. Large and small APs appear to have digested many organelles. At late stages of degeneration, the nucleus is condensed but remains intact, even after engulfment by phagocytes (Fig. $2 H$ ). In the inset to Figure $2 H$, APs are enlarged to show that double membranes are common in portions of cytoplasm engulfed by a macrophage (M).

\section{Neuronal survival in postnatal Hq and ATG7 mutant mice}

The number of surviving spinal and cranial MNs and SCG neurons in P5 Hq mutants and in P15 ATG-7 mutant mice did not differ significantly from control WT mice (Table 2). Because nor- mal developmental PCD of hypoglossal and facial MNs, SCG neurons, and granule cells in the DG extends into the first postnatal week, we also asked whether early postnatal treatment of $\mathrm{Hq}$ mutants with the broad spectrum caspase inhibitor Q-VD-OPH rescued postnatal PCD of these neuronal populations. Daily Q-VD-OPH treatment from P2 to P4 did not affect the number of neurons present on P5 in either WT or Hq mutant mice (Table 2). Based on a DEVD cleavage assay, the Q-VD-OPH inhibitor reduced caspase activation to the same extent in WT control and Hq mutant mice (WT, $15.3 \%$ reduction, $p=0.0159, n=6, t$ test; $\mathrm{Hq}, 21 \%$ reduction, $p=0.0372, n=9, t$ test). The number $\left(\right.$ mean \pm SD) of TUNEL ${ }^{+}$cells per section in the DG of both WT and $\mathrm{Hq}$ mutant on $\mathrm{P} 5$ was also reduced after treatment with Q-VD-OPH (WT vehicle, $2.56 \pm 1.07, n=6$, vs WT Q-VD$\mathrm{OPH}, 1.56 \pm 0.46, n=6, p<0.03$, $t$ test; Hq vehicle, $2.46 \pm 1.37$, $n=9$, vs Hq Q-VD-OPH, $1.37 \pm 0.72, n=9, p<0.02$, $t$ test). The number of caspase ${ }^{+}$or TUNEL ${ }^{+}$granule cells in the DG of P5 ATG7 mutant mice did not differ from WT controls (data not shown). Together, these data indicate that neither AIF nor ATG7 are required for normal PCD of developing neurons and they also suggest that caspase inhibition in AIF-deficient mice reduces type 1 PCD (apoptosis) but not PCD by an alternative caspaseindependent (autophagic?) pathway. At the end of the normal period of PCD, the number of surviving neurons in AIF-deficient and ATG7 KO mice is comparable with that of WT animals. We also did not observe any evidence for the lack of engulfment of dead or degenerating neurons in the ATG7 KO as has been recently reported for retinal neurons in ATG5 mutant embryos (Qu et al., 2007).

\section{Discussion}

\section{Normal PCD in the absence of Apaf-1}

Previous studies of the in vivo role of caspases in the normal PCD of developing neurons have shown that, although caspase activation is involved in most cases of neuronal PCD, they are only necessary for the PCD of immature neurons or neuronal precursors at early stages when neurogenesis is still ongoing (Kuan et al., 2000; Boya and de la Rosa, 2005). Genetic deletion or pharmacological inhibition of caspases prevents this early type of PCD in the nervous system, whereas similar perturbations are ineffective in preventing the normal PCD of postmitotic neurons at later stages when synaptic connections are being established (Oppenheim et al., 2001a; Yaginuma et al., 2001; Bredesen et al., 2006). In the absence of caspases, these more mature postmitotic neurons undergo quantitatively normal amounts of PCD albeit by a different caspase-independent pathway that is distinct from type 1 apoptotic PCD (Oppenheim et al., 2001a; Yaginuma et al., 2001).

Apaf-1, which is part of the apoptosome required for activation of downstream caspases (e.g., caspase-3) in the type 1 apoptotic cascade of neuronal PCD, is also required for the death of immature neurons and neuronal precursor cells (Cecconi et al., 1998, 2004; Yoshida et al., 1998; Honarpour et al., 2000; Cregan et 
al., 2002; Cozzolino et al., 2004). However, its role in the normal PCD of more mature postmitotic neurons has not been systematically examined. We now demonstrate for the first time in vivo that, after the genetic deletion of Apaf-1, several populations of postmitotic neurons in the central and peripheral nervous system undergo normal amounts of PCD and that the degeneration occurs by a morphological pathway distinct from that observed in the same neuronal populations in the presence of Apaf-1. These results differ from the observations of Honarpour et al. (2001a) who report increased neuron numbers (i.e., reduced PCD) in the DRG and trigeminal ganglion of Apaf-1 KO mice on E16.5. Although the reason for the different results is not clear, it may be attributable to the small sample size ( $n=1$ per group) and the apparent failure to do blinded cell counts.

\section{The mode of PCD in the absence of Apaf-1}

In the absence of caspases, postmitotic developing neurons exhibit cellular degenerative changes that differ significantly from the morphological changes observed in normal neurons. Caspase-deficient neurons are $\mathrm{TUNEL}^{-}$, fail to express activated caspases, have reduced chromatin condensation, cytoplasmic vacuolization, mitochondrial and RER dilatation, and apparent increases in autophagosomes (Oppenheim et al., 2001a,b; Yaginuma et al., 2001). As described below, we observed similar changes in degenerating neurons deficient in Apaf-1.

In addition, however, the Apaf-1-deficient neurons also appear to exhibit increased numbers of APs and Ls compared with caspase-deficient neurons. Although APs are occasionally present in normal neurons and even in neurons undergoing type 1 apoptotic PCD (Chu-Wang and Oppenheim, 1978; Clarke, 1990; Xue et al., 1999), the increased abundance of APs in caspase- and Apaf-1-deficient neurons suggests that PCD in these cases may be occurring by a type 2 autophagic pathway. Consistent with this argument, we observe degenerating Apaf-1deficient neurons with abundant autophagosomes that have been phagocytized by macrophages. This observation, together with the normal amount of cell loss observed in both caspase- and Apaf-1-deficient embryos, indicates that PCD is occurring, and thus makes it less likely that autophagy in this situation is playing a role independent of the execution phase of PCD (Lang-Rollin et al., 2003; Akdemir et al., 2006; Yoshimori, 2007). However, we cannot entirely exclude the possibility that autophagic activity in this situation is acting as a cleanup-like mechanism in cells that have been induced to undergo cell death by a nonautophagic, caspase-independent pathway (Rubinsztein et al., 2005). One way to test this would be to examine cell death in Apaf-1 mutants that also lack key autophagy genes. Although there has been a debate over whether autophagy is a nonapoptotic form of PCD or a prosurvival mechanism (Lockshin and Zakeri, 2004; Eskelinen, 2005; Levine and Yuan, 2005), there is a growing consensus that, depending on the circumstances, it can serve both roles (Uchiyama, 2001; Yue et al., 2002; Shimizu et al., 2004; Komatsu et al., 2006; Nixon, 2006; Berry and Baehrecke, 2007; Calderó et al., 2007; Fimia et al., 2007).

In the classic review by Clarke (1990), type 2 autophagic PCD is included as one of the three major types of developmental PCD. However, the extent to which type 2 PCD occurs in the developing nervous system in the absence of injury or perturbation is not clear (Yue et al., 2002; Ravikumar et al., 2004; Yu et al., 2004; Tarabal et al., 2005; Nixon, 2006). In the case of the populations of neurons examined here, type 2 PCD appears to play little if any role in normal PCD in the presence of caspases and Apaf-1. Only in their absence does the degeneration exhibit evidence of type 2 autophagy as a possible alternative default-like pathway of PCD. Consistent with this argument, we find that normal type 1 PCD occurs in the nervous system of mice deficient in the key autophagy-related gene 7 (ATG7) (Komatsu et al., 2006). Although we cannot exclude the possibility that other autophagyrelated genes may mediate normal neuronal PCD, for the neuronal populations examined here we consider this to be unlikely.

Another PCD pathway that we considered as possibly being involved in normal neuronal cell death or in cell death in caspaseor Apaf-1-deficient mice is one that uses the proapoptotic AIF. AIF is a mitochondrial protein that induces caspase-independent neuronal apoptosis after translocation to the nucleus (Cheung et al., 2006). AIF has been reported to be essential for normal PCD during early embryogenesis (Joza et al., 2001), for PCD of embryonic cortical neurons (Cheung et al., 2006), and is also involved in cell death in the postnatal and adult brain after irradiation (Fukuda et al., 2004) and hypoxia-ischemia (Wang et al., 2004; Culmsee et al., 2005; Zhu et al., 2006; Blomgren et al., 2007; Cao et al., 2007). We examined PCD in several populations of developing neurons in $\mathrm{Hq}$ mutant mice that have an $\sim 80 \%$ reduction in the expression of AIF (Klein et al., 2002). Neuron numbers are normal on $\mathrm{P} 5$ in both untreated $\mathrm{Hq}$ mice and in $\mathrm{Hq}$ mice after treatment with the broad-spectrum caspase inhibitor Q-VDOPH. From these data, we conclude that AIF is not required for normal neuronal PCD or for neuronal PCD after caspase inhibition. It could be argued, however, that the $20 \%$ residual AIF expression in the $\mathrm{Hq}$ mutant may be sufficient to mediate normal PCD. Although we cannot entirely exclude this possibility, we consider it unlikely because cell death of neurons in other situations in the neonatal and adult brain is reduced significantly in Hq mutant mice (Zhu et al., 2006). Although not examined here, it seems likely that PCD in postnatal WT and Hq mutant neurons after caspase inhibition may also involve autophagy (Oppenheim et al., 2001; Yaginuma et al., 2001).

In the last 10 years, it has been increasingly recognized that there are diverse mechanisms that can mediate developmental as well as injury-induced PCD (Sperandio et al., 2000; Boya and de la Rosa, 2005; Chipuk and Green, 2005; Bredesen et al., 2006; Blomgren et al., 2007; Brunet et al., 2007). In the present study, we present evidence consistent with this contemporary view by demonstrating that in the absence of a key player in type 1 apoptotic PCD (Apaf-1), developing postmitotic neurons nonetheless undergo PCD but by a nonapoptotic caspase-independent pathway that exhibits signs of autophagy. Additionally, because we also demonstrate that the neuronal populations examined here undergo normal caspase-dependent apoptotic PCD in the absence of a key autophagy gene (ATG7), autophagy may serve primarily as an alternative fail-safe mode of PCD that is only activated when type 1 apoptotic PCD is prevented (Kroemer and Martin, 2005; Pattingre et al., 2005; Maiuri et al., 2007).

\section{References}

Akdemir F, Farkas R, Chen P, Juhasz G, Medved'ová L, Sass M, Wang L, Wang X, Chittaranjan S, Gorski SM, Rodriguez A, Abrams JM (2006) Autophagy occurs upstream or parallel to the apoptosome during histolytic cell death. Development 133:1457-1465.

Berry DL, Baehrecke EH (2007) Growth arrest and autophagy are required for salivary gland cell degradation in Drosophila. Cell 131:1137-1148.

Blomgren K, Leist M, Groc L (2007) Pathological apoptosis in the developing brain. Apoptosis 12:993-1010.

Boya P, de la Rosa EJ (2005) Cell death in early neural life. Birth Defects Res 75:281-293.

Bredesen DE, Rao RV, Mehlen P (2006) Cell death in the nervous system. Nature 443:796-802.

Brunet N, Tarabal O, Protero-Otín M, Oppenheim RW, Esquerda JE, Calderó 
J (2007) Survival and death of mature avian motoneurons in organotypic slice culture: trophic requirements for survival and different types of degeneration. J Comp Neurol 501:669-690.

Buss RR, Sun W, Oppenheim RW (2006) Adaptive roles of programmed cell death during nervous system development. Annu Rev Neurosci 29:29-35.

Calderó J, Tarabal O, Cassanova A, Ciutat D, Casas C, Llado J, Esquerda JE (2007) Excitotoxic motoneuron disease in chick embryo evolves with autophagic neurodegeneration and deregulation of neuromuscular innervation. J Neurosci Res 85:2726-2740.

Cao G, Xing J, Xiao X, Liou AKF, Gao Y, Yin XM, Clark RSB (2007) Critical role of calpain I in mitochondrial release of apoptosis-inducing factor in ischemic neuronal injury. J Neurosci 27:9278-9293.

Cecconi F, Alverez-Bolado G, Meyer BI, Roth KA, Gruss P (1998) Apaf-1 (CED-4 homolog) regulates programmed cell death in mammalian development. Cell 94:727-737.

Cecconi F, Roth KA, Dolgov O, Munarriz E, Anokhin K, Gruss P, Salminen M (2004) Apaf-1-dependent programmed cell death is required for inner ear morphogenesis and growth. Development 131:2125-2135.

Cheung EC, Melanson-Drapeua L, Cregan SP, Vanderluit JL, Ferguson KL, McIntosh WC, Park DS, Bennett SA, Slack RS (2005) Apoptosisinducing factor is a key factor in neuronal cell death propagated by Baxdependent and Bax-independent mechanisms. J Neurosci 25:1324-1334.

Cheung EC, Joza N, Steenaart NAE, McClellan KA, Neuspiel M, McNamara S, MacLaurin JG, Rippstein P, Park DS, Shore GC, McBride HM, Penninger JM, Slack RS (2006) Dissociating the dual roles of apoptosisinducing factor in maintaining mitochondrial structure and apoptosis. EMBO J 25:4061-4073.

Chipuk JE, Green DR (2005) Do inducers of apoptosis trigger caspaseindependent cell death? Nat Rev Mol Cell Biol 6:268-275.

Chu-Wang IW, Oppenheim RW (1978) Cell death of motoneurons in chick embryo spinal cord: a light and electron microscopic study of naturally occurring and induced cell loss during development. J Comp Neurol 177:33-58.

Clarke PG (1990) Developmental cell death: morphological diversity and multiple mechanisms. Anat Embryol 181:195-213.

Clarke PG (1998) Apoptosis versus necrosis: how valid a dichotomy for neurons? In: Cell death and diseases of the nervous system (Koliatsos VE, Ratan RR, eds), pp 3-28. Totowa, NJ: Humana.

Clarke PG, Oppenheim RW (1995) Neuron death in vertebrate development: in vivo methods. Methods Cell Biol 46:277-321.

Cozzolino M, Ferraro E, Ferri A, Rigamonti D, Quondamatteo F, Ding H, Xu ZS, Ferrari F, Angelini DF, Rotilio G, Cattaneo E, Carri MT, Cecconi F (2004) Apoptosome inactivation rescues proneural and neural cells from neurodegeneration. Cell Death Differ 11:1179-1191.

Cregan SP, Fortin A, MacLaurin JG, Callaghan SM, Cecconi F, Yu S-W, Dawson TM, Dawson VL, Park DS, Kroemer G, Slack RS (2002) Apoptosis-inducing factor is involved in the regulation of caspaseindependent neuronal cell death. J Cell Biol 158:507-517.

Culmsee C, Shu C, Landshamer S, Becattini B, Wagner E, Pellechia M, Blomgren K, Plesnila N (2005) Apoptosis-inducing factor triggered by poly(ADP-ribose polymerase) and bid mediates neuronal cell death after oxygen-glucose deprivation and focal cerebral ischemia. J Neurosci 25:10262-10272.

Eskelinen E-L (2005) Doctor Jekyll and Mister Hyde: autophagy can promote both cell survival and cell death. Cell Death Differ 12:1468-1472.

Fimia GM, Stoykova A, Romagnoli A, Giuta L, Bartolomeo SD, Nardacci R, Corazzari M, Fuoco C, Ucar A, Schwartz P, Gruss P, Piacentini M, Chowdhury K, Cecconi F (2007) Ambral regulates autophagy and development of the nervous system. Nature 447:1121-1125.

Fukuda H, Fukuda A, Zhu C, Korhonen L, Swanpalmer J, Hertzman S, Leist M, Lannering B, Kindholm D, Björk-Eriksson T, Marky I, Blomgren K (2004) Irradiation-induced progenitor cell death in the developing brain is resistant to erythropoitin in treatment and caspase inhibition. Cell Death Differ 11:1166-1178.

Grieshammer U, Lewandoski M, Prevette D, Oppenheim RW, Martin GR (1998) Muscle-specific cell ablation conditional upon cre-mediated DNA recombination in transgenic mice leads to massive spinal and cranial motoneuron loss. Dev Biol 197:234-247.

Hakem R, Hakem A, Duncan GS, Henderson JT, Woo M, Soengas MS, Elia A, de la Pompa JL, Kagi D, Khoo W, Potter J, Yoshida R, Kaufman SA, Lowe
SW, Penninger JM, Mak TW (1998) Differential requirement for caspase 9 in apoptotic pathways in vivo. Cell 94:339-352.

Hao Z, Duncan GS, Chang CC, Elia A, Fang M, Wakeham A, Okada H, Calzascia T, Jang YJ, You-Ten A, Yeh WC, Ohashi P, Wang X, Mac TW (2005) Specific ablation of the apoptotic functions of cytochrome c reveals a differential requirement for cytochrome $c$ and Apaf-1 in apoptosis. Cell 121:579-591.

Harris BS, Franz T, Ullrich S, Cook S, Bronson RT, Davisson MT (1997) Forebrain overgrowth ( $f \circ g$ ): a new mutation in the mouse affecting neural tube development. Teratology 55:231-240.

Honarpour N, Du C, Richardson JA, Hammer RE, Wang X, Herz J (2000) Adult Apaf-1-deficient mice exhibit male infertility. Dev Biol 218:248-258

Honarpour N, Tabuchi K, Stark JM, Hammer RE, Südhof TC, Parada LF, Wang X, Richardson JA, Herz J (2001a) Embryonic neuronal death due to neurotrophin and neurotransmitter deprivation occurs independent of Apaf-1. Neuroscience 106:263-274.

Honarpour N, Gilbert SL, Lahn BT, Wang X, Herz J (2001b) Apaf-1 deficiency and neural tube closure defects are found in fog mice. Proc Natl Acad Sci USA 98:9683-9687.

Joza N, Susin SA, Dougas E, Stanford WL, Cho SK, Li CY, Sasaki T, Ella AJ, Cheng HY, Ravagnan L, Ferri KF, Zamzami N, Wakeham A, Hakem R, Yoshida H, Kong YY, Nak TW, Zúñiga-Pflücker JC, Kroemer G, Penninger JM (2001) Essential role of the mitochondrial apoptosisinducing factor in programmed cell death. Nature 410:549-554.

Klein JA, Longo-Guess CM, Rossmann MP, Seburn KL, Hurd RE, Frankel WN, Bronson RT, Ackerman SL (2002) The harlequin mouse mutation down-regulates apoptosis-inducing factor. Nature 419:367-374.

Komatsu M, Waguri S, Chiba T, Murata S, Iwata J-I, Tanida I, Ueno T, Koike M, Uchiyama Y, Kominami E, Tanaka K (2006) Loss of autophagy in the central nervous system causes neurodegeneration in mice. Nature 441:880-884.

Kroemer G, Martin SJ (2005) Caspase-independent cell death. Nat Med 11:725-730.

Kuan C-Y, Roth KA, Flavell RA, Rakic P (2000) Mechanisms of programmed cell death in the developing brain. Trends Neurosci 23:291-297.

Kuida K, Zheng TS, Na S, Kuan C-Y, Karasuyama H, Rakic P, Flavell RA (1996) Decreased apoptosis in the brain and premature lethality in CPP 32-deficient mice. Nature 384:368-372.

Kuida K, Haydar TF, Kuan C-Y, Gu Y, Gaya C, Karasuyama H, Su MS-S, Rakic P, Flavell RA (1998) Reduced apoptosis and cytochrome c-mediated caspase activation in mice lacking caspase 9. Cell 94:325-337.

Lang-Rollin IC, Rideout HJ, Noticewala M, Stefanis L (2003) Mechanisms of caspase-independent neuronal death: energy depletion and free radical generation. J Neruosci 23:11015-11025.

Levine B, Yuan J (2005) Autophagy in cell death: an innocent convict? J Clin Invest 115:2679-2688.

Lockshin RA, Zakeri Z (2004) Apoptosis, autophagy and more. Int J Biochem Cell Biol 36:2405-2419.

Maiuri MC, Toumelin GL, Criollo A, Rain J-C, Gautier F, Juin P, Tasdemir E, Pierron G, Troulinaki K, Tavernarakis N, Hickman JA, Geneste O, Kroemer G (2007) Functional and physical interaction between Bcl- $\mathrm{X}_{\mathrm{L}}$ and a BH3-like domain in Beclin-1. EMBO J 26:22527-22539.

Nixon RA (2006) Autophagy in neurodegenerative disease: friend, foe or turncoat? Trends Neurosci 29:528-535.

Oppenheim RW (1991) Cell death during development of the nervous system. Annu Rev Neruosci 14:453-501.

Oppenheim RW, Flavell RA, Vinsant S, Prevette D, Kuan C-Y, Rakic P (2001a) Programmed cell death of developing mammalian neurons after genetic deletion of caspases. J Neurosci 21:4752-4760.

Oppenheim RW, Green DR, Ethell DW, Prevette D, Vinsant S (2001b) Programmed cell death of developing post-mitotic neurons in Apaf-1 mutant mice. Soc Neurosci Abstr 27:29.1.

Pattingre S, Tassa A, Qu X, Garuti R, Liang XH, Mizushima N, Packer M, Schneider MD, Levine B (2005) Bcl-2 antiapoptotic proteins inhibit beclin 1-dependent autophagy. Cell 122:927-939.

Peters A, Palay SL, Webster H deF (1976) The fine structure of the nervous system. Philadelphia: W. B. Saunders.

Qu X, Zou Z, Sun Q, Luby-Phelps K, Cheng P, Hogan RN, Gilpin C, Levine B (2007) Autophagy gene-dependent clearance of apoptotic cells during embryonic development. Cell 128:931-946. 
Ravikumar B, Vacher C, Berger Z, Davies JE, Luo S, Oroz LG, Scaravilli F, Easton DF, Duden R, O'Kane CJ, Rubinsztein DC (2004) Inhibition of mTOR induces autophagy and reduces toxicity of polyglutamine expansions in fly and mouse models of Huntington disease. Nat Genet 36:585-595.

Rubinsztein DC, DiFiglia M, Heintz N, Nixon RA, Qin Z-H, Ravikumar B, Stefanis L, Tolkovsky A (2005) Autophagy and its possible roles in nervous system diseases, damage and repair. Autophagy 1:11-22.

Shimizu S, Kanasecki T, Mizushima N, Mizuta T, Arakawa-Kobayashi S, Thompson CB, Tsujmoto Y (2004) Role of Bcl-2 proteins in a nonapoptotic programmed cell death dependent on autophagy genes. Nat Cell Biol 6:1221-1228.

Sperandio S, de Belle I, Bredesen DE (2000) An alternative, nonapoptotic form of programmed cell death. Proc Natl Acad Sci USA 97:14376-14381

Tarabal O, Calderó J, Casas C, Oppenheim RW, Esquerda JE (2005) Protein retention in the endoplasmic reticulum, blockade of programmed cell death and autophagy selectively occur in spinal cord motoneurons after glutamate receptor-mediated injury. Mol Cell Neurosci 29:283-298.

Thaler J, Harrison K, Sharma K, Lettieri K, Kehrl J, Pfaff SL (1999) Active suppression of interneuron programs within developing motor neurons revealed by analysis of homeodomain factor HB9. Neuron 23:675-687.

Uchiyama Y (2001) Autophagic cell death and its execution by lysosomal cathepsins. Arch Histol Cytol 64:233-246.

Wang H, Yu S-W, Koh DW, Lew J, Coombs C, Bowers W, Federoff HJ, Poirier GG, Dawson TM, Dawson VL (2004) Apoptosis-inducing factor substitutes for caspase executioners in NMDA-triggered excitotoxic neuronal death. J Neurosci 24:10963-10973.

Wang X, Karlsson JO, Zhu C, Bahr BA, Hagberg H, Blomgren K (2001)
Caspase-3 activation after neonatal rat cerebral hypoxia-ischemia. Biol Neonate 79:172-179.

Winseck AK, Oppenheim RW (2006) An in vivo analysis of Schwann cell programmed cell death in embryonic mice: the role of axons, glial growth factor, and the pro-apoptotic gene Bax. Eur J Neurosci 24:1-13.

Wright KM, Vauaghn AE, Deshmukh M (2007) Apoptosome dependent caspase- 3 activation pathway is non-redundant and necessary for apoptosis in sympathetic neurons. Cell Death Differ 14:625-633.

Xue L, Fletcher GC, Tolkovksy AM (1999) Autophagy is activated by apoptotic signaling in sympathetic neurons: an alternative mechanism of death execution. Mol Cell Neurosi 14:180-198.

Yaginuma H, Shiraiwa N, Shimada T, Nishiyama K, Hong J, Wang S, Momoi T, Uchiyama Y, Oppenheim RW (2001) Caspase activity is involved in, but is dispensable for, early motoneuron death in the chick embryo cervical spinal cord. Mol Cell Neurosci 18:168-182.

Yoshida H, Kong YY, Yoshida R, Elia AJ, Hakem A, Hakem R, Penninger JM, Mak TW (1998) Apaf-1 is required for mitochondrial pathways of apoptosis and brain development. Cell 94:739-750.

Yoshimori T (2007) Autophagy: paying Charon's toll. Cell 128:833-836.

Yu L, Allva A, Su H, Dutt P, Freundt E, Welsh S, Baehricke EH, Lenardo MJ (2004) Regulation of an ATG7-beclin 1 program of autophagic cell death by caspase- 8 . Science 304:1500-1502.

Yue Z, Horton A, Bravin M, DeJager PL, Selimi F (2002) A novel protein complex linking the $\delta 2$ glutamate receptor and autophagy: implications for neurodegeneration in Lurcher mice. Neuron 35:921-933.

Zhu C, Wang X, Huang Z, Qiu L, Xu F, Vahsen N, Nilsson M, Eriksson PS, Hagberg H, Culmsee C, Plesnila N, Kroemer G, Blomgren K (2006) Apoptosis-inducing factor is major contributor to neuronal loss induced by neonatal cerebral hypoxia-ischemia. Cell Death Differ 13:1-10. 